\title{
Review: glycoprotein Ilb/Illa inhibitors reduced death or myocardial infarction in acute coronary syndromes not routinely scheduled for revascularisation
}

Source of funding: not stated.

For correspondence: Dr E Boersma

University Hospital Rotterdam, Rotterdam, The Netherlands. boersma@thch.azr.nl.

\section{Boersma E, Harrington RA, Moliterno DJ, et al. Platelet glycoprotein IIb/IIIa inhibitors in acute coronary syndromes: a meta-analysis of all major randomised clinical trials. Lancet 2002 Jan 19;359:189-98.}

\section{QUESTION: In patients with acute coronary syndromes not routinely scheduled for early coronary revascularisation, what is the efficacy and safety of glycoprotein (GP) Ilb/IIla inhibitors?}

Glycoprotein (GP) IIb/III inhibitors v placebo or control for acute coronary syndromes not routinely scheduled for coronary revascularisation*

\begin{tabular}{|c|c|c|c|c|}
\hline Outcomes & $\begin{array}{l}\text { GP Ilb/Illa } \\
\text { inhibitors }\end{array}$ & $\begin{array}{l}\text { Placebo } \\
\text { or control }\end{array}$ & $\operatorname{RRR}(95 \% \mathrm{Cl})$ & NNT (Cl) \\
\hline Death or Ml at 5 days & $5.7 \%$ & $6.9 \%$ & $15 \%(7$ to 22$)$ & 97 (67 to 223$)$ \\
\hline Death or $\mathrm{Ml}$ at 30 days & $11 \%$ & $12 \%$ & $8 \%(2$ to 14$)$ & 106 (63 to 479 ) \\
\hline Death at 5 days & $1.2 \%$ & $1.3 \%$ & $7 \%(-14$ to 24$)$ & Not significant \\
\hline Death at 30 days & $3.4 \%$ & $3.7 \%$ & $9 \%(-3$ to 18$)$ & Not significant \\
\hline $\mathrm{CABG}$ or $\mathrm{PCl}$ at 5 days & $18 \%$ & $20 \%$ & $4 \%(-1$ to 8$)$ & Not significant \\
\hline $\mathrm{CABG}$ or $\mathrm{PCl}$ at 30 days & $38 \%$ & $39 \%$ & $1 \%(-2$ to 4$)$ & Not significant \\
\hline \multirow[t]{2}{*}{$\begin{array}{l}\text { Death or Ml at } 30 \text { days } \\
\text { Men only }\end{array}$} & $10 \%$ & $13 \%$ & $17 \%(10$ to 23$)$ & 47 (36 to 82$)$ \\
\hline & & & RRI (Cl) & NNH (Cl) \\
\hline Women only & $12 \%$ & $10 \%$ & $13 \%(1$ to 26$)$ & 73 (37 to 1072$)$ \\
\hline Major bleeding at 30 days & $2.4 \%$ & $1.4 \%$ & $61 \%$ (35 to 92$)$ & 121 (80 to 207) \\
\hline
\end{tabular}

${ }^{*} \mathrm{CABG}=$ coronary artery bypass grafting; $\mathrm{MI}=$ myocardial infarction; $\mathrm{PCl}=$ percutaneous coronary intervention Other abbreviations defined in glossary; RRR, RRI, NNT, NNH, and Cl calculated from data in article.

\section{COMMENTARY}

The acute coronary syndromes are unstable angina pectoris (UA) and non-ST elevation MI (NSTEMI). The meta-analysis by Boersma et al summarises the treatment results of 4 platelet GP IIb/IIIa inhibitors from 6 randomised trials. The combined end point of death or non-fatal MI was reduced, but the individual end point reductions did not reach statistical significance. Of the drugs evaluated in the 6 trials, eptifibatide and tirofiban, but not lamifiban or abciximab, are currently approved for use in the USA for patients with acute coronary syndromes not routinely scheduled for coronary revascularisation.

Two subgroup analyses are noteworthy. First, the treatment benefit was present in patients with positive troponin values (odds ratio [OR] $0.85,95 \%$ CI 0.71 to 1.03 ) but not in those with negative values (OR 1.17, CI 0.94 to 1.44). One conclusion might be that use of these agents should be limited to patients with NSTEMI. Many patients diagnosed with UA are actually misdiagnosed and do not have acute vascular injury; thus, they would not benefit from antithrombotic treatment. Second, although not scheduled for coronary revascularisation, $38 \%$ of patients actually had PCI or CABG within 30 days. They benefited from treatment (OR 0.89 , CI 0.80 to 0.98 ), whereas those who did not have revascularisation did not appear to benefit (OR 0.95, CI 0.86 to 1.05). The 2002 American College of Cardiology-American Heart Association guidelines ${ }^{1}$ conclude that "GP IIb/IIIa inhibitors are of substantial benefit in patients with UA/NSTEMI who undergo PCI; they are of modest benefit in patients who are not routinely scheduled to undergo PCI (but who may do so); and they are of questionable benefit in patients who do not undergo PCI." The women in this analysis were more likely to have negative troponin values and less likely to have revascularisation, which probably explains the reported sex difference in treatment effect. Current trials are evaluating combinations of $\mathrm{GP} \mathrm{IIb} / \mathrm{III}$ antagonists, clopidogrel, and enoxaparin.

Eric R Bates, MD University of Michigan Ann Arbor, Michigan, USA

1 American College of Cardiology/American Heart Association 2002 guideline update for the management of patients with unstable angina and non-ST-segment elevation myocardial infarction. Bethesda: American College of Cardiology/American Heart Association, 2002 (www.acc.org/clinical/statements.htm.

\section{Data sources}

Trials reported from 1990 were identified by searching Medline with the terms unstable angina, myocardial infarction, and platelet aggregation inhibition; reviewing scientific sessions abstracts in 3 cardiology journals; and scanning bibliographies of retrieved articles.

\section{Study selection}

Studies were selected if they randomly allocated $\geqslant 1000$ patients who had acute coronary syndromes without persistent ST-segment elevation to a GP Illb/IIIa inhibitor or to placebo or control treatment and if early $(<48 \mathrm{~h})$ coronary revascularisation during drug infusion was not recommended.

\section{Data extraction}

Data from individual patients were extracted on baseline characteristics (age, sex, cardiac history and medication, blood pressure, and heart rate), medication detail, dates and times of randomisation, death, myocardial infarction (MI), coronary artery bypass grafting (CABG), percutaneous coronary intervention (PCI), stroke, intracranial haemorrhage, major bleeding, and 30 days of follow up. The main efficacy outcome was a composite of death or non-fatal MI, and the main safety outcome was major bleeding.

\section{Main results}

6 trials ( $\mathrm{n}=31402$, mean age $64 \mathrm{y}, 65 \%$ men) were included in the analysis. Patients who received GP $\mathrm{IIb} / \mathrm{III}$ inhibitors had a lower risk for the composite end point of death or MI than did those who received placebo or control treatment at 5 days and 30 days, but they did not differ for mortality or receipt of either CABG or PCI (table). Subgroup analysis showed that men who received GP IIb/IIIa inhibitors had a reduced risk for the composite end point, whereas women had an increased risk (table). GP IIb/IIIa inhibitors increased risk for major bleeding complications (table).

\section{Conclusion}

In patients with acute coronary syndromes not routinely scheduled for early coronary revascularisation, glycoprotein $\mathrm{IIb} / \mathrm{III} a$ inhibitors reduced the combined end point of death or myocardial infarction but increased major bleeding complications. 